Article

\title{
Shell Shock and the Legacy of the Victorian Past in the Present: Remembering WWI in Pat Barker's Another World
}

\section{Elodie Rousselot $\mathbb{D}$}

School of Area Studies, History, Politics and Literature, University of Portsmouth, Milldam Building, Burnaby Road, Portsmouth PO1 3AS, UK; elodie.rousselot@port.ac.uk

Received: 5 December 2019; Accepted: 6 March 2020; Published: 16 March 2020

\begin{abstract}
In her 1998 novel Another World, Pat Barker draws from a topic on which she has written previously with great success-the First World War and the experiences of its combatants-and yet approaches that topic from a completely different perspective. The novel returns to the Great War to consider notions of 'shell shock', attitudes towards WWI veterans, and the problems surrounding remembering past violence, but what is perhaps surprising about Another World is that it uses a Victorian storyline to address these concerns, and presents the First World War through the means of references to nineteenth-century culture.
\end{abstract}

Keywords: WWI; contemporary historical fiction; shell shock; Pat Barker; Another World; 19thC cultural discourses

In her 1998 novel Another World, Pat Barker draws from a topic on which she has written previously with great success-the First World War and the experiences of its combatants-and yet approaches that topic from a completely different perspective. The novel returns to the Great War to consider notions of 'shell shock', attitudes towards WWI veterans, and the problems surrounding remembering past violence, but what is perhaps surprising about Another World is that it uses a Victorian storyline to address these concerns, and presents the First World War through the means of references to nineteenth-century culture. ${ }^{1}$ Indeed, the novel focuses on the last days of WWI veteran Geordie, who, in his approaching death, is experiencing a return of the post-traumatic symptoms he had first experienced after his return from the Front. Yet his increasingly worrying condition-as well as the military horrors which gave rise to it-are overlooked for most of the novel. Instead, the narrative shifts towards his grandson Nick and the discovery the latter makes of a mysterious nineteenth-century portrait in his living-room. The painting is believed to be of a local affluent Victorian family, the Fanshawes, and to be linked to a murder committed within that family.

The story of this disturbing murder becomes a growing source of fascination for Nick and a means of escaping the troubling memories of WWI Geordie attempts to share with him. This essay argues that this is representative of the role references to the Victorian past tend to play in contemporary historical fiction, even in those texts that return to other historical periods (in this instance, the First World War). I have discussed elsewhere how in such fiction these neo-Victorian references act as a source of distraction for the characters, one that is ultimately shown to be misguided and detrimental

1 Early signs of this technique are visible in Barker's Regeneration trilogy (Barker 1991-1995), where the violence of the Front is compared to the killings of Jack the Ripper ('Odd, he thought, that the fascination with the Ripper and his miserable five victims should persist, when half of Europe was at it' (586; original emphasis)), and where protagonist Billy Prior's fugue state is compared to a 'Jekyll and Hyde' condition (527). Barker's use of nineteenth-century cultural references in her treatment of the First World War is more pronounced in Another World however, as we will see. 
(see Rousselot 2016). These neo-Victorian references also tend to take the shape of references to medical research, as we will see in the treatment of 'shell shock' in Barker's novel. To that effect, the term 'shell shock' is used in this essay as a means of highlighting the set of cultural and historical values that influenced initial understandings of the condition. ${ }^{2}$ The novel's superimposition of different time frames - the Victorian age, the First World War, and the present—-therefore highlights the continuity of the Victorian past in the present, but also reveals the problems underpinning such use of the nineteenth century in contemporary culture. Ultimately, the tension between the novel's different time frames culminates in a shocking revelation which brings the reader's attention back onto the legacy of the First World War in the present, and away from the easy diversion of scandals set in the Victorian age. In the process, the text explores different attitudes to remembering and narrating past suffering, from 'the safe and domesticated versions of the past that are offered by the heritage industry' (Whitehead 2004, p. 138) to versions of past horror that cannot be romanticised for indulgent consumption in the present.

One such response to this type of past horror in the novel is shell shock: as already mentioned, Geordie suffers from a repeat of the symptoms he first experienced after his time in the trenches. As well as nightmares, flashbacks, hallucinations in which he mistakes his daughter for a German soldier, and episodes of altered consciousness during which he believes he is on patrol on No Man's Land, he cannot be deterred from the belief that it is his 'bayonet wound that's killing him' (Barker 1999, p. 57), a wound that has 'given him no trouble for eighty years' (Barker 1999, p. 62; original emphasis), rather than the advanced stages of his cancer. Geordie's shell shock symptoms, as a form of trauma emanating from the past and as a type of injury that has not-or cannot-heal, offer a compelling illustration of 'the power of old wounds to leak into the present' (Barker 1999, p. 74). This double perception of shell shock (both as a literal, physical condition and as the figurative presence of the past in the present) also provides a useful way of approaching the different attitudes to remembering and narrating past suffering in the novel.

This is visible early on in the narrative at the occasion of a trip to the WWI memorial in Thiepval, Northern France, a trip Nick reluctantly takes with Geordie at the latter's request, and as a last chance to make the journey together. Yet the memorial, with its 'annihilating abstractions', produces an unexpected reaction in Nick: 'He was repelled by it. The monument towered over the landscape, but it didn't soar as a cathedral does. [ ... ] It seemed to Nick that this place represented not a triumph over death, but the triumph of death' (Barker 1999, pp. 72-73; original emphasis). Despite its architectural grandeur and its majestic attempt to transform the First World War's narratives of suffering into an aesthetic expression, the memorial seems to fail where Nick is concerned: as the latter admits, 'he hasn't succeeded in telling himself about Thiepval yet' (Barker 1999, p. 85), and has been unable to 'come to terms with it' (Barker 1999, p. 74). Nick seems incapable of partaking of the process of remembering the deaths of WWI signified by the monument, and despite the latter's imposing structure, the conflict as a whole remains an 'abstraction', one which cannot be grasped-or healed-through this form of narration.

In contrast, the gruesome narratives of the nineteenth century create a different response in Nick: although disturbed by the Victorian family portrait discovered in his new home, Nick 'goes to Fleete House [the Fanshawe family estate] in a mood of "pre-packaged nostalgia"' (Barker 1999, p. 65 qtd in Whitehead 2004, p. 138), and in search of further clues as to the meaning of the painting. He discovers that two-year-old James Fanshawe, son of William and his second wife Isobel, was taken from his room one night and killed in a macabre mise en scène. No one was ever convicted of the murder, even though James's half-brother and half-sister Robert and Muriel Fanshawe, William's children from a previous marriage, were tried for the crime. They were eventually acquitted, for lack of evidence. Nick finds the details of James Fanshawe's death in a book he buys in the Fleete House gift shop,

2 In more recent medical discussions of the condition that term has been replaced by expressions such as 'post-traumatic stress syndrome' or 'post-traumatic stress disorder'. 
but chooses to keep the story to himself, concluding that 'It's not as if any useful purpose would be served by telling' his family (Barker 1999, p. 113). In this instance, Nick dismisses the purpose of narrating acts of past violence, yet the fact that the murder story is sold in the family estate's gift shop illustrates its ready availability for popular consumption, and confirms the commercial framework within which the contemporary appetite for the grisly deeds of the Victorian age can be indulged. In fact, a similar appetite for the nineteenth century is displayed by most of the characters in the novel: Nick's daughter Miranda compares their house to that of Wuthering Heights (Barker 1999, p. 12) and wishes 'she had a book to read, like Jane Eyre' (Barker 1999, p. 21), while his step-son Gareth dreams of turning a neighbouring waste ground into 'a real bog, like in the Hound of the Baskervilles', so that 'anybody who tried to find the den would sink into the mud with screams and yells' (Barker 1999, p. 132). In both instances, these cultural references to the nineteenth century act as a means of avoiding sources of discomfort in the present: for Gareth, the retreat into the horror stories of the Victorian age points towards his anxiety at the prospect of being bullied at his new school, while 'the vision of the madwoman in the attic offers [Miranda] a romanticized escape from the troubling reality of her mother's illness' and recent admission into a psychiatric hospital (Whitehead 2004, p. 140).

But if the violence of the Victorian era is deemed preferable to that of the present day, or at any rate preferable to that of the First World War, the characters' attempted escape into that violence is short-lived and shown to have potentially dangerous consequences. Indeed, unbeknownst to Nick, and in a storyline that closely echoes that of the Fanshawe murder, Gareth comes very close to killing his half-brother Jasper, with Miranda as a possible passive witness (the nature of her involvement is never confirmed). Although tragedy is avoided, this act of violence seems to be connected to the mysterious apparition of a young girl in a long skirt at different points in the narrative, possibly a ghostly manifestation of Muriel Fanshawe, who 'always insisted on her innocence' in the murder of her half-brother (Barker 1999, p. 113), or a hallucination on the part of the characters. The narrative hovers between these two possibilities without offering any conclusive explanation. Either way, these apparitions seem to distract the characters from the reality of the violence they are about to commit, in Gareth's and possibly Miranda's case, and from the reality of the violence taking place in their very domestic environment, in Nick's. Ironically, the latter is so preoccupied with the gruesome details of the Victorian past that he fails to notice the striking parallels between his family situation and that of the Fanshawes'. On the surface, therefore, the novel's neo-Victorian motif appears to facilitate the characters' retreat into the ghastly deeds of the nineteenth century; instead of facilitating that retreat however, the novel highlights the misguided nature of the characters' attempts to seek in nineteenth-century horror a relief from present-day anxieties. The novel thus seems to problematise straight forward uses of the neo-Victorian in contemporary fiction: rather than enabling a return to the Victorian past, the text is concerned instead with exploring the characters' complex relationship with that past.

In this context, the twofold nature of shell shock, as a condition that speaks literally and figuratively of the presence of the past in the present, is useful where that relationship with the Victorian past is concerned. Indeed, if the 'novel comes as close as possible to an imitation of the symptoms of trauma' (Ganteau 2013, p. 31), I would argue that shell shock in particular acts as a metaphor for the condition experienced by the characters, a condition which manifests itself figuratively through their constant return to the nineteenth century, and literally, through the possible hallucinations they experience as a result. As already mentioned, the narrative fails to confirm whether the series of mysterious sightings the characters are witness to are genuine ghostly manifestations of the Victorian past in the present, or the result of their own delusions. Either way, the notion of shell shock in the novel seems to convey the mixed feelings of fascination and unrest associated with the legacy of the nineteenth century in the

3 Jean-Michel Ganteau's essay offers an innovative perspective on trauma in the novel, arguing that Barker achieves a specific ethics of representation in the text through the use of romance strategies that subvert the novel's realistic mode of expression from within (Ganteau 2013, pp. 17-18). 
present. As a symptom of that legacy, and of the complex relationship it spells out with the characters, the condition offers a means of grasping some of that complexity.

Additionally, shell shock can also be seen as a symptom of the legacy of the Victorian age in the present in so far as initial understandings of the illness relied heavily on nineteenth-century cultural discourses, especially those relating to gender. First appearing in 1915 in the British medical journal The Lancet, the term 'shell shock' was coined by British physician Charles Myers who subsequently admitted that it was 'a singularly ill-chosen' expression (Myers 1940, p. 25). Initially believed to be caused by the proximity of exploding shells, the term described the range of symptoms suffered by soldiers during and after WWI. But as Elaine Showalter notes, 'shells were not to blame; and in men who were already exhausted or convalescing, the breakdown could be so gradual that the term "shock" too was a misnomer' (Showalter 1987, p. 168). Rather than being organic in origin, it soon became clear that the condition was linked to the psychological strain of warfare, and according to Showalter, that it was exacerbated by the 'social expectations of the masculine role in war' (Showalter 1987, p. 171). The influence of these gender expectations in the medical practice of the time seems confirmed by the fact that 'psychiatrists never tired of implying that the man who collapsed under the strain of combat was "feminine"' (Bourke 1999, p. 253), and is visible 'in the desire of First World War psychologists to restore soldiers to self-control and manly "character"' (Loughran 2015, p. 250). As Geordie admits in the novel, 'the truth is I was shell-shocked, but they didn't seem to talk about that in them days. You just had to shut up and get on with it' (Barker 1999, p. 150). Moreover, in the context of a culture that saw the war 'as a catalyst of maturity', or as 'a training ground where boys were turned into men' (Meyer 2009, p. 2), succumbing to shell shock was also read in terms of a regression to childhood, whereby 'the failures of shell-shocked men were as much those of immaturity as of effeminacy' (Meyer 2009 , p. 4).

Whether the 'Great War was a crisis of masculinity' (Showalter 1987, p. 171), or a crisis of maturity, it was clearly 'a trial of the Victorian masculine ideal' (Showalter 1987, p. 171). Indeed the 'heroic visions' of masculine behaviour and other 'masculinist fantasies' which underpinned medical understandings of shell shock at the beginning of the twentieth century were cultural constructs left over from the Victorian age, circulated for instance in such texts as 'Rider Haggard's male adventure stories' or in 'the romantic military poems of Tennyson' (Showalter 1987, p. 169), and based on nineteenth-century readings of gender that defined masculinity 'in relation to class, education and authority' (Meyer 2009 , p. 3). The character of William Fanshawe in the novel, who never once betrayed any emotion during the trial of his two eldest children for the murder of his youngest son, illustrates clearly the link between gender, class and authority in the nineteenth century. In addition, initial theories about shell shock linked the condition to 'hereditary taint' (Showalter 1987, p. 170), or to the notion of an inbuilt weakness in the patient which predisposed the latter to mental breakdowns, thereby confirming once again the influence of Victorian cultural discourses (in this instance, 'Darwinian psychiatry' (Showalter 1987, p. 169)) in medical understandings of the condition. The influence of these discourses is further exemplified in Myers's comment that 'the frequency of "shell shock" in any unit [of combat] is an index of its lack of discipline and loyalty' (Myers 1940, pp. 38-39). This perception of shell shock as a failure of obedience (and possibly a sign of treason), rather than simply a medical condition, is visible in Geordie's observation that 'for all you were supposed to be heroes and all that you didn't have to say much before they accused you of malingering' (Barker 1999, p. 150). In this instance, the masculine heroic ideal underpinning medical attitudes to WWI veterans is shown to be the very instrument through which constraining gender normative values are enforced. Even subsequently with the more humane approach of 'analytic' doctors, the treatment shell-shocked soldiers received very much relied on the re-establishment of these values. ${ }^{4}$ As a result, 'although the experience of 1914-18 did force

4 This process is described in Barker's Regeneration trilogy (Barker 1991-1995) through the work of 'analytic' doctor W.H.R. Rivers, who helped his patients identify the traumatic events from which their symptoms stemmed, and through 're-education' encouraged them to control these symptoms by better understanding the effect of these traumatic events. 
popular awareness of the potentially traumatic effects of war, it did not completely overturn [ ... ] the fundamental tenets of Victorian and Edwardian ideals of masculine character' (Loughran 2015, pp. 250-51). Rather, it 'reinforced the importance of living up to the values embodied in this ideal' (Loughran 2015, p. 251).

If initial understandings of the illness relied heavily on nineteenth-century cultural discourses, contemporary perceptions of shell shock and WWI veterans are still influenced by the same ideologies: according to Tracey Loughran, "when we talk about "shell-shock", we often unwittingly reinforce older ideals of heroism' (Loughran 2015, p. 251). She argues that current understandings of the veterans' situation should not rely on the notion that they were victims or heroes of the First World War; rather, their medical condition should be approached independently of any consideration of their military conduct: the 'truly radical reappraisal of social and cultural expectations of military masculinity will come when it is accepted [ ... ] that heroism does not need to be part of our discussions of "shell-shock"' (Loughran 2015, p. 251). This issue is raised in the novel where the deliberate refusal to offer the reader the expected heroic narrative associated with WWI veterans becomes a means of 'confronting our own attitudes towards heroism, cowardice and the demands of war' (Loughran 2015, p. 251). Early on in the text, it is made clear that Geordie is 'an ordinary man who, by living long, had become extraordinary' (Barker 1999, p. 69). The social consideration given to war veterans in contemporary culture is deliberately played down in this instance, to bring into focus the effect that the veterans' gradual decline in number has had on that social consideration, seemingly above and over the fact of their participation in conflict.

The text further complicates the expected cultural construction of the character of the veteran as hero or victim with the shocking revelation that Geordie may have killed his brother while both were fighting in the Battle of the Somme. The narrative remains ambiguous as to whether the killing was deliberate or an act of mercy to hasten Harry's impending death as a result of the fatal injuries he had sustained. This ambiguity is exacerbated in part by Geordie's shell-shocked condition which prevents him from remembering the scene clearly. Indeed, although Geordie suffers from flashbacks which force him to re-live the ordeal of his time in the trenches, he ironically cannot remember seeing his brother's wounds, and therefore cannot confirm whether his killing was justified or not. The novel also reveals the deep rivalry that existed between Geordie and Harry, and the fact that on several occasions prior to the latter's death Geordie contemplated the idea of perpetrating violence on his brother. By deliberately blurring the lines between heroic behaviour and cowardly murder, the text challenges current cultural expectations of war veterans, and highlights the continued legacy of Victorian notions of military masculinity which underpin these expectations.

The novel thus prevents the character of the shell-shocked veteran to be constructed as hero or victim due to the suggestion of possible fratricide associated with Geordie. In addition, the reoccurrence of this particular crime in each of the novel's time frames brings into focus the notion of (historical) repetition, and presents the latter as hinging on a failure to remember past trauma. Indeed, although Nick congratulates himself on his decision not to tell his family about the Fanshawe murder, reasoning that 'It's easy to let oneself be dazzled by false analogies-the past never threatens anything as simple, or as avoidable, as repetition' (Barker 1999, p. 277), the reader realises how wrong he is, and the novel makes clear that the past very much threatens, and very nearly succeeds, in being repeated within his family. In turn, this failure to remember past trauma can be linked to the condition of shell shock: commenting on the pathological nature of repetition in cases of shell shock (or 'war neuroses'), Sigmund Freud outlines in Beyond the Pleasure Principle (1920) how the patient 'is obliged to repeat the repressed material as a contemporary experience instead of, as the physician would prefer to see, remembering it as something belonging to the past' (Freud 2011, p. 24; original emphasis). According to

From this perspective, however, it seems the onus remained on the patients to address their symptoms and resolve their effects, in the context of a therapeutic practice that appeared to still rely on the masculine military ideals of rationality and self-possession circulated in the nineteenth century. 
Freud, the repetition of a past traumatic experience in the present in the context of cases of shell shock is contrary to the process of 'remembering' such experience, and signifies an inability to integrate the latter in the conscious. This seems to be the case with Geordie who, despite re-experiencing repeatedly the horror of his time in the trenches, cannot remember the scene of his brother's death. ${ }^{5}$ In Freudian terms therefore, the characters' compelled return to the Victorian past is in fact contrary to the process of remembering it, and testifies instead to their inability to integrate the memory of that past in a conscious narrative. In this context, Gareth's (and possibly Miranda's) ill-treatment and attempted killing of Jasper symbolically point towards the repetition of the traumatic experience of the Fanshawe murder in the present, a traumatic experience which has been repressed by Nick's failure to acknowledge it. Paradoxically therefore, the characters' repetition of the gruesome deeds of the nineteenth century in the novel signifies both their refusal to remember such deeds, and their inability to forget the same. From this perspective, the condition of shell shock highlights once again the characters' complex relationship with the legacy of the Victorian age in the present.

Additionally, the notion of shell shock is also linked to the broader issue of remembering past trauma, and what shape that process should take. Indeed, in spite of Nick's belief that 'The only true or useful thing that can be said about the past is that it's over. It no longer exists' (Barker 1999, p. 86), the narrative tells a different story. This is visible in relation to Nick's decision not to tell his family about the Fanshawe murder, a decision that has almost tragic consequences, as we have seen. This notion of remembering past trauma is raised in relation to the different forms of violence depicted in the text, from the state-sanctioned horrors of WWI to the transgression of murders carried out by children and between siblings. ${ }^{6}$ Indeed, the narrative is written in the shadow of the Jamie Bulger murder committed in Liverpool in 1993, and makes a passing reference to three figures smudged on a video surveillance screen, an older boy taking a toddler by the hand while his companion strides ahead, eager for the atrocity to come' (Barker 1999, p. 3). While the notion of violence perpetrated by children against children remains intolerable in contemporary culture and is repressed in the novel by Nick's refusal to acknowledge it, the violence of the Front is commemorated by memorials such as Thiepval, where narratives of suffering are conveyed through art. Here again, the novel prevents such easy distinction by bringing into focus the arbitrary nature of the moral and legal boundaries we draw between acceptable and unacceptable forms of violence. As Judith Seaboyer notes, the novel 'responds to the anxiety surrounding the particularity of child-on-child violence by exploring moral dilemmas rather than by reiterating moral positions' (Seaboyer 2011, p. 73). To that effect, Pat Barker 'shifts the ground away from simplistic certainties that enable us either to lay blame or to displace it' (Seaboyer 2011, p. 73). This is visible in the novel's suggestion that the First World War's context of state-sanctioned killing has rendered possible horrific deeds such as fratricide: for Geordie, if children do not act on their murderous impulses, it is because 'They don't get the chance, do they, most of the time?' (Barker 1999, p. 264) From this perspective, it seems warfare provides an opportunity for carrying out deviant deeds.

This also has implications in relation to the different attitudes to remembering past suffering explored in the novel, for instance in the context of the characters' fascination with the gruesome deeds of the Victorian age. Although such fascination carries its own risks, as we have seen, it does not lead to the same level of ethical questioning as the process of commemorating similar deeds set during WWI or in the present (as with the Jamie Bulger murder). This is the case with Geordie's violence against his brother: Nick cannot keep the disturbing nature of this act at the safe historical distance

5 In fact, according to Anne Whitehead, 'Barker draws on "Beyond the Pleasure Principle", a key moment in the theorizing of trauma, for her portrait of Geordie' (Whitehead 2004, p. 131). She notes, however, 'a crucial difference between Geordie and the soldiers of whom Freud writes, in that Geordie suffers his nightmares eighty years after the end of the war' (Whitehead 2004, p. 131).

6 If no longer a child, Geordie was seventeen when he allegedly killed his brother, and therefore under the legal age of conscription for the First World War. 
of the past, as he does with the Fanshawe murder. Geordie's possible fratricide therefore resists the process of romanticisation at work with the violence of the Victorian past in the novel, and visible also in the heroic narratives of WWI. The novel drives this point home by symbolically linking the characters of Robert Fanshawe and Geordie through the historic ground of the Battle of the Somme, where the former met his death and the latter was involved in murder: this shared battleground further brings into focus the similarities between both characters' actions. The text thus draws from instances of violence that prove morally challenging to the present to contemplate different attitudes to remembering and narrating past suffering, and to reveal the problems underpinning the reduction of such suffering to aesthetic paradigms (for instance with the Thiepval memorial, or the book in the Fleete House gift shop).

But if 'the combat of (and with) the past is mirrored in the domestic skirmishes of the present' in the novel (Becker 1999, p. 6), the motif of fratricide in particular highlights the link between remembering/repeating past violence in the context of contemporary attitudes to family values. Such values, the text suggests, stem from another legacy of the Victorian age in the present: that of the idealised nineteenth-century family. As Anne Whitehead notes, the novel 'powerfully contests the political rhetoric, prevalent throughout the 1990s, that sought to inculcate family values through the example of the Victorian family' (Whitehead 2004, p. 138). This contestation is carried out by shedding light on more deviant forms of nineteenth-century family relations however, as with the Fanshawe murder, and by revealing the continued influence of Victorian family values in the present. From this point of view, fratricide offers a means of exploring the mixed feelings of fascination and unease associated with the legacy of these values. Such conflicted attitude seems epitomised in the character of Robert Fanshawe in the text: a child murderer, his death in the Battle of the Somme seems to redeem his violent character by affording him heroic status, and enabling his posthumous re-insertion into the family narrative. This is visible in the commemorative tablet dedicated to his and his brother James's deaths and displayed in the local church: both brothers are remembered on a single tablet, and in a common expression of mourning, which seems to conveniently side-step the fact that Robert very probably was responsible for James's murder. In this instance, the Fanshawes' public act of remembrance places side by side 'the innocent and the guilty, the murderers and the victims' (Barker 1999, p. 278), while their attempt to re-affirm their abidance by domestic ideals and to sanctify these in the pious context of the local church has the inadvertent effect of symbolically bringing together fratricide and military warfare. The same way the distinction between both forms of violence is shown to be an arbitrary construction, the novel reveals the constructed nature of the values upon which the idealised Victorian family rests.

This is further conveyed in the epitaph adorning Robert's and James's commemorative tablet: 'If any question why we died, Tell them, because our fathers lied' (Barker 1999, p. 277). It is taken from 'Common Form' (1918), one of Rudyard Kipling's Epitaphs of the War, written after his son John was killed in action during WWI. Despite the fact that Robert and James Fanshawe died in very different circumstances, here again a single reason seems to be invoked for their demise: the 'lies' of their 'father'. As Nick observes, 'What's strange is the determined linking of the two deaths, the conviction of guilt for both' (Barker 1999, p. 277). But it is very possible that the epitaph points to the broader question of responsibility in the novel: although William Fanshawe did not commit any murders himself, his armaments factory, with which he made his fortune during the First World War, was responsible for more deaths-including possibly that of his son Robert - than the murderous deeds of his two children. In addition, Fanshawe's silence at Robert's and Muriel's trial, and therefore, his possible withholding of crucial information in the conviction of James's murderer, can be seen as a form of lie by omission. If the meaning of the epitaph remains open to interpretation in the text, it nevertheless facilitates a parallel between Kipling (who, as a father, 'lied' or rather used his influence to have his son enlisted into the Irish Guards, despite the latter having been rejected on the grounds of his poor eyesight), William Fanshawe, and Nick (who, also as a father, lies to his family by hiding the truth about the Fanshawe murder, a lie which, one could argue, almost costs his son Jasper his life). The notion of 
'lying' fathers and 'dying' children is echoed in the broader motif of betrayals committed within the family, such as fratricide, and explored from a variety of perspectives in the narrative.

In fact, the novel suggests that false constructs of filial love and domestic bliss based on Victorian domestic ideals have prevented such betrayals from being openly acknowledged, thus facilitating their repetition through time. Indeed, if the Fanshawes are presented as the embodiment of these ideals, with William as the 'Victorian paterfamilias' (Barker 1999, p. 40), presiding over the lives of his family members and over those of many in the local community who depend on his armaments factory for their livelihood, clearly their domestic situation was not as harmonious as William was keen to suggest. In Nick's case, remembering and narrating past violence are pitted against preserving domestic bliss, and as we have seen, his choice to prioritise the latter inadvertently places his family at greater risk. The pervasive effect of these false constructs is suggested in the text through the use of troubling metaphors that rely on natural imagery, with, for instance, recurring references to dead animals and decaying plants. The notion of domestic bliss, for example, is belied early on in the narrative by the ominous discovery of a 'blackbird's nest, full of dead fledglings' Nick makes when trimming a rose bush to reveal the name 'Fanshawe' carved into the lintel of his new home (Barker 1999, p. 12). Furthermore, the Fanshawe family portrait Nick and his family uncover is compared to 'a mass of rotting vegetation, long submerged' having risen 'suddenly to the surface of a pond' (Barker 1999, p. 42). More disturbingly, the portrait features William Fanshawe's 'erect penis spring[ing] from the unbuttoned flies, as thick and pale as the decaying cabbage stalks in the kitchen garden' (Barker 1999, p. 40). In these instances, the 'surfacing' of some form of past suffering stemming from acts considered morally reprehensible (such as child neglect, or possibly incest) is conveyed through the use of references to natural objects traditionally perceived as life-giving ('blackbird's nest'), or nurturing ('cabbage stalks in the kitchen garden'). These natural objects, which have been diverted from their intended purpose, further imply the anomalous nature of the Fanshawe family relations. More broadly, this use of imagery calls into question the cultural constructs defining what is considered 'natural' and what is not, and brings to light the similar processes of construction underpinning the notion of the Victorian family in the text.

If Heather Nunn and Anita Biressi note that the novel 'reveals the artificiality of cultural distinctions between proper and improper responses' in the context of 'taboo subjects normally silenced' (Biressi and Nunn 2005, p. 261), I would add that such cultural distinctions are also brought into question in relation to non-taboo subjects in the narrative. This is visible, for instance, through Nick's reaction to his pregnant wife nursing their son:

There's something disturbing about [Jasper's] broad sticky hand kneading Fran's breast. [ ... ] The drained face, the straggly hair, the huge belly, the skinny, sharp-boned cat-with-too-many-litters look, it reminds Nick of some awful Victorian pamphlet advocating the virtues of self-restraint. [ ... ] The truth is he's repelled by her (Barker 1999, p. 31)

Instead of a bonding experience that promotes family unity, the scene triggers feelings of repulsion in Nick. Moreover, Nick's endorsement of false constructs of family love and domestic bliss sits oddly with the anti-filial feelings he experiences in this passage, confirming once again the inadequacy of these constructs. As already mentioned, the latter blind him to the parallels between his domestic situation and that of the Fanshawes', and prevent him from acknowledging the acts of violence taking place within his family. In contrast, nurturing parental care (such as breastfeeding) is presented in negative terms in this scene, visible, for instance, in the disturbing suggestion of incest hinted at in the reference to Jasper's 'hand kneading Fran's breast'. More broadly, the notion of filial nurture is undermined in the extract above to convey a bleak vision of blood relations, one that is linked to the idea of unrestrained excess ('cat-with-too-many-litters look'), and the concomitant notion of parental neglect (echoed in the earlier example of the 'blackbird's nest, full of dead fledglings'). This is emphasised by the nineteenth-century codes of moral conduct ('Victorian pamphlet') invoked by Nick to justify his reaction. Although he seems aware of the problems underpinning such codes of conduct (the pamphlet is qualified as 'awful'), the fact that he is 'repelled' by his wife seems to confirm his abidance by the values they promote, and his belief in their power to act as a form of regulatory influence over excessive 
natural instincts. In the context of the novel, such belief seems ironic: as the rest of the narrative suggests, the Victorian age was hardly the epitome of 'self-restraint'. Nick's investment in these nineteenth-century cultural discourses is therefore shown to be similarly misguided, and confirms, yet again, the adverse effect of the legacy of Victorian family values in the present. More broadly, the cultural constructions of what constitutes appropriate family relations come under scrutiny in the text to reveal how such constructions are in fact detrimental to the process of acknowledging transgressions committed within the domestic setting, and to preventing the reoccurrence of such transgressions.

In conclusion, the novel's return to the memory of the First World War is operated via a neo-Victorian motif which seemingly shifts the focus of the narrative towards the fulfillment of an indulgent fascination with the gruesome deeds of the nineteenth century. Yet, rather than enabling this fascination, the narrative brings to light how such motifs obscure the real source of horror in the text, thereby offering a different understanding of the presence of the neo-Victorian in contemporary fiction. The narrative also confirms the conflicted position the neo-Victorian occupies in contemporary re-imaginings of other historical periods, where it acts both as a means of avoiding unresolved conflicts, and as the source of more such conflicts. From this perspective, the notion of shell shock seems to mirror the novel's attitude to Victorian culture, conveying as it does both the return of past horrors in the present, and the failure of the present to remember such horrors. Furthermore, as a condition shaped by the cultural discourses of the Victorian age, and as a symptom of the legacy of such discourses in the present, shell shock-like the neo-Victorian-highlights contemporary culture's complex relationship with the nineteenth century. In the end however, the narrative reveals how the influence of the Victorian past has to be laid to rest, while the deeds of the living have to be faced and dealt with in the present.

Funding: This research received no external funding.

Conflicts of Interest: The authors declare no conflict of interest.

\section{References}

Barker, Pat. 1991-1995. The Regeneration Trilogy. London: Penguin Books.

Barker, Pat. 1999. Another World. London: Penguin Books. First published 1998.

Becker, Alida. 1999. An Interview: Old War Wounds. New York Times Book Review, May 16.

Biressi, Anita, and Heather Nunn. 2005. In the Shadow of Monstrosities: Memory, Violence, and Childhood in Another World. In Critical Perspectives on Pat Barker. Edited by Sharon Monteith, Margaretta Jolly, Nahem Yousaf and Ronald Paul. Columbia: University of South Carolina Press, pp. 254-65.

Bourke, Joanna. 1999. An Intimate History of Killing: Face-to-Face Killing in Twentieth-Century Warfare. London: Granta Press.

Freud, Sigmund. 2011. Beyond the Pleasure Principle. In On Freud's Beyond the Pleasure Principle. Edited by Salman Akhtar and Mary O'Neil. London: Karnac Books, pp. 13-70. First published 1920.

Ganteau, Jean-Michel. 2013. “The Past Won't Fit into Memory without Something Being Left Over": Pat Barker's Another World, in between Narrative Entropy and Vulnerability. In Trauma and Romance in Contemporary British Literature. Edited by Jean-Michel Ganteau and Susana Onega. New York: Routledge, pp. 17-33.

Loughran, Tracey. 2015. Masculinity, Trauma and "Sell-shock". Psychologist 28: 250-51.

Meyer, Jessica. 2009. Separating the Men from the Boys: Masculinity and Maturity in Understandings of Shell Shock in Britain. Twentieth-Century British History 20: 1-22. [CrossRef] [PubMed]

Myers, Charles S. 1940. Shell-Shock in France. Cambridge: Cambridge University Press.

Rousselot, Elodie. 2016. Treating the Victorian Medical Past in Melissa Pritchard's "Captain Brown and the Royal Victoria Military Hospital". Victoriographies 6: 165-80. [CrossRef]

Seaboyer, Judith. 2011. "It Happened Once ... It Can Happen Again. Take Care": Gothic Topographies in Pat Barker's Another World. In Re-Reading Pat Barker. Edited by Pat Wheeler. Newcastle upon Tyne: Cambridge Scholars, pp. 63-78. 
Showalter, Elaine. 1987. Male Hysteria: W.H.R. Rivers and the Lessons of Shell Shock. In The Female Malady: Women, Madness, and English Culture, 1830-1980. London: Virago, pp. 167-94.

Whitehead, Anne. 2004. The Past as Revenant: Trauma and Haunting in Pat Barker's Another World. Critique 45: 129-46. article distributed under the terms and conditions of the Creative Commons Attribution (CC BY) license (http://creativecommons.org/licenses/by/4.0/). 